\title{
An Expeditious Enantiospecific Total Synthesis of (+)-7-epi-Goniofufurone
}

Kavirayani R. Prasad,* Shivajirao L. Gholap Synlett 2005, 2260.

The stereochemical representations of some compounds were incorrectly drawn in Schemes 1 and 2. The corrected schemes are:<smiles>O=C1C[C@H]2OC([C@H](O)c3ccccc3)[C@@H](O)[C@H]2O1</smiles>

1<smiles>[R5][C@H](c1ccccc1)[C@H]1OC(C)(C)O[C@H]1[C@H](O)CCC=C</smiles><smiles>C=CC=C</smiles><smiles>C=CC(=O)C(OC(C)(C)C)C(O)C(=O)O</smiles><smiles>CC(C)COC(=O)C(OC(C)(C)C)C(N)=O</smiles>

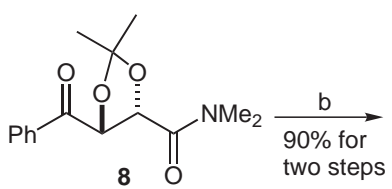<smiles>CN(C)C(=O)C(OC(C)(C)C)C(OC(C)(C)C)C(O)c1ccccc1</smiles><smiles>C=CCCC(=O)C1OC(C)(C)OC1[C@H](O)c1ccccc1</smiles><smiles>C=CCCC(O)C1OC(C)(C)OC1C(O)c1ccccc1</smiles>

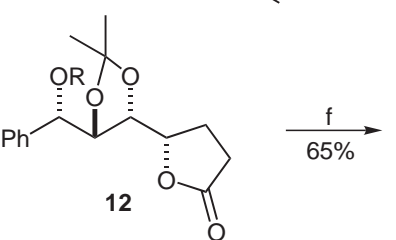

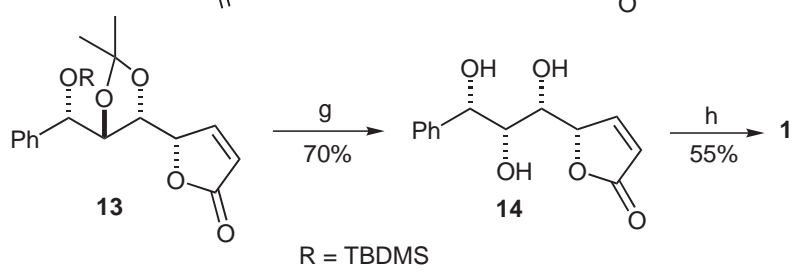

Scheme 2 